\title{
FAULT PROGNOSTIC BASED ON AR-LSSVR FOR ELECTROLYTIC CAPACITOR
}

\author{
Ming Yin, Yanyi Xu, Xiaohui Ye, Shaochang Chen, Hongxia Wang, Feng Xie
}

Original scientific paper

This paper puts forward a method of fault prognostic based on Autoregressive - Support Vector Regression Method (AR-LSSVR) for electrolytic capacitor. Because the electrolytic capacitor is low in cost and large in volume, it is widely used in power electronic circuits. Firstly it introduces the basic model and the fault prognostic algorithm of the AR, LSSVM and AR-LSSVR. The AR-LSSVR prediction model combines the prediction algorithm advantage of the LSSVR and the AR model and complements the two to enhance prediction accuracy. It introduces the flow chart of fault trend prediction based on AR-LSSVR. Finally, the AR-LSSVR model is applied to the Buck circuit. The results indicate that the AR-LSSVR model performs better in trend prediction of electrolytic capacitor.

Keywords: AR-LSSVR; electrolytic capacitor; fault prognosis

\section{Predviđanje greške primjenom AR-LSSVR za elektrolitički kondenzator}

Izvorni znanstveni članka

U radu se opisuje metoda predviđanja greške na osnovu Autoregressive - Support Vector Regression Metode (AR-LSSVR) za elektrolitički kondenzator. Budući da je elektrolitički kondenzator jeftin, a velik, uveliko se primjenjuje u elektroničkim krugovima. Najprije se daje osnovni model i algoritam za predviđanje greške za AR, LSSVM i AR-LSSVR. Model AR-LSSVR kombinira prednosti algoritma LSSVR-a i modela AR te ih dopunjuje kako bi se povećala točnost predviđanja. Daje se dijagram toka predviđanja pojave greške na temelju AR-LSSVR. Konačno se AR-LSSVR model primjenjuje na Buck strujni krug. Rezultati pokazuju da je predviđanje greške elektrolitičkog kondenzatora bolje primjenom modela AR-LSSVR.

Ključne riječi: AR-LSSVR; elektrolitički kondenzator; predviđanje greške

\section{Introduction}

At present, various methods are applied to failure prediction of electronic devices. They can be grouped into three kinds according to complexity, prediction performance, and scope of application: methods based on statistical distribution, methods based on data driving and methods based on models. Among the three methods, their complexity and prediction accuracy increase with themselves, while the scope of application decreases.

Among them, methods based on models are mostly applied to electromechanical systems such as aircrafts and rotation bodies. In comparison to the study on complicated electronic system, the study on failure prediction still lags behind as the failure mode and the failure mechanism are intricate. Fan Geng et al. [3] proposed an adaptive correlation based on artificial fish swarm algorithm, and verified the performance of the method through the fault prediction of high voltage power supply and duo klystron of radar transmitter. Zhu et al. [17] proposed a prediction method of gas in power equipment oil based on vector regression. Qi Tao [4] proposed an analogous circuit fault prediction method based on PSO optimized LSSVM penalty factor and nuclear parameter. Jiang Y. Y. et al. [5] proposed the fault prediction of power electronic circuit-level based on LSSVM method. Zhang A. H. et al. [6] proposed a robust LSSVR simulation circuit performance online evaluation strategy, and realized the output prediction of analog circuit. According to the characteristics of electronic equipment fault, based on SVR algorithm, supplemented with other intelligent algorithms, the fault prediction of electronic equipment can be solved.

The block diagram based on data-driven prediction is shown in Fig. 1. First of all, accede to the historical data of equipment or system, and select suitable prediction model algorithms, and pre-process the data in order to input to the prediction model. Then use the equipment or system state to predict the future state of equipment or system, at the same time according to its life cycle model to predict the remaining useful life.

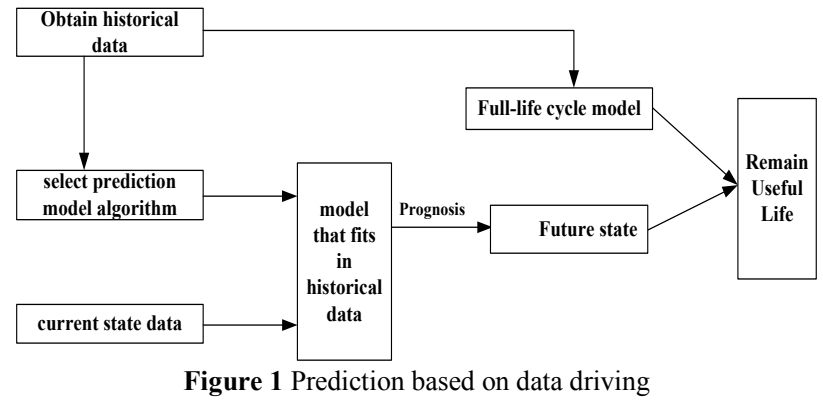

Distinguished from mechanical equipment, failure prediction of electronic devices may be affected by various factors, which brings difficulty to the prediction.

(1) High integration level. Built-in data check can be difficult. As the degradation and failure of electronic devices is a micro physical-chemical process, it is almost impossible to perform built-in data check.

(2) Complex failure mechanism and damage model. Physical and mathematical models are hard to build up. Electronic system failure results from the comprehensive interaction of load. As failure mechanisms are multi-fold and the time stress damage is intricate, single physical failure model is not enough to describe electronic system failure. Existing studies focus much on the correlation between the single load intensity and the damage while making light of the superposed damage.

(3) Difficult collection of life-cycle characteristic parameters. At present, dominant research methods for failure prediction of electronic devices such as neural network, rely much on the collection of life-cycle 
characteristic parameters. Usually, they seek for premonitory signals, such as the migration of voltage.

\section{AR-LSSVR model \\ 2.1 AR prediction model}

The Autoregressive model (AR model) is a typical time series signal model. It is featured by linear prediction, where data before or after the $N^{\text {th }}$ data is deduced according to $N$ given data.

\subsubsection{Fundamental principle}

AR model presumes that time series are produced from the rational transfer function driven by white noise. The correlation between input and output of $A R(p)$ model is shown in Eq. (1):

$$
x(n)=-\sum_{k=1}^{p} a_{k} x(n-k)+w(n),
$$

where $x(n)$ is the output sequence, $a_{k}$ is the auto-regressive parameter, $w(n)$ is zero mean, the power of white noise is $\sigma_{w}^{2}$ and $Y(t)=y(t)+\varepsilon(t)$ is the order. The system transfer function of $A R(p)$ is:

$$
H(Z)=\frac{1}{A(Z)}=\frac{1}{1+a_{1} z^{-1}+a_{2} z^{-2} \cdots+a_{p} z^{-p}}
$$

\subsubsection{Parameter solving method}

Parameter solving methods of AR model include the least square method, the Yule-Walker method and the Burg method. The least square method uses model parameters obtained from simulation based on AR model. This paper selects Yule-Walker method and Burg method as samples to instruct on how to solve AR model parameters.

(1) Yule-Walker method

The Yule-Walker method is also named autocorrelation method. The Yule-Walker equation confirms the correlation between AR model parameters and signal autocorrelation function:

$$
\left[\begin{array}{ccccc}
R_{x x}(0) & R_{x x}(-1) & R_{x x}(-2) & \cdots & R_{x x}(-p) \\
R_{x x}(1) & R_{x x}(0) & R_{x x}(-1) & \cdots & R_{x x}-(p-1) \\
\vdots & \vdots & \vdots & & \vdots \\
R_{x x}(p) & R_{x x}(p-1) & R_{x x}(p-2) & \cdots & R_{x x}(0)
\end{array}\right]\left[\begin{array}{c}
1 \\
a_{p, 1} \\
\vdots \\
a_{p, p}
\end{array}\right]=\left[\begin{array}{c}
\sigma_{w}^{2} \\
0 \\
\vdots \\
0
\end{array}\right]
$$

where, $R_{x x}(p)$ is the autocorrelation function; $a_{p, i}(i=1,2$, $\ldots, p)$ is the $i^{\text {th }}$ parameter of p-order AR model. When $i=$ $p, a_{p, p}$ is called partial correlation coefficient (PARCOR) or reflection coefficient.

This thesis employs the Levinson-Dubin recursive algorithm. According to the Yule-Walker equation, AR model parameter is on the following. $a_{p, p}=-\frac{R_{x x}(p)+\sum_{k=1}^{p-1} a_{p-1, k} R_{x x}(p-k)}{\sigma_{p-1}^{2}}$

$a_{p, k}=a_{p-1, k}+a_{p, p} a_{p-1, p-k}$

$a_{p}^{2}=\left(1-a_{p, p}^{2}\right) \sigma_{p-1}^{2}$

$\sigma_{0}^{2}=R_{x x}(0)=E\left(x^{2}(n)\right)$

(2) Burg method

The Burg method does not need autocorrelation function. It is different from the Lebinson-Dubin method in that when calculating the reflection coefficient, the former not only ensures that the mean square error of forward prediction is the minimum, but also makes the sum of mean square error of forward and backward prediction the minimum. According to the Burg method, for AR model parameters are in the following.

$a_{p, p}=-\frac{2 \sum_{n} e_{p-1}(n) b_{p-1}(n-1)}{\sum_{n} e_{p-1}^{2}(n) b_{p-1}^{2}(n-1)}$

$a_{p, k}=a_{p-1, k}+a_{p, p} a_{p-1, p-k}$

$e_{p}(n)=e_{p-1}(n)+a_{p, p} b_{p-1}(n-1)$

$b_{p}(n)=x(n)+\sum_{k=1}^{p} a_{p, p-k} x(n-k)$

where, $b_{p}(n)$ is $x(n)$ forward error of $n$ point sequence and $e_{p}(n)$ is $x(n)$ backward error of $n$ point sequence.

\subsection{LSSVR prediction algorithms}

When there are too many samples, the standard support vector regression algorithm is no longer suitable to solve quadratic programming, dragging the computing speed. But the Least Squares Support Vector Regression (LSSVR) is well applied to make a change. It succeeds many advantages of SVM, and thus is widely applied to prediction of time series.

The LSSVR regression function is:

$f(x)=w^{T} \phi(x)+b \quad w \in R^{n}, b \in R$

where, $f(x)$ is the prediction output, $\varphi(x)$ is the non-linear function, $x$ is the input, $w$ is the weight, $w^{T}$ is the transposition of $w, b$ is the deviation, $R^{n}$ is $N$-dimensional space of real numbers and $R$ is real numbers.

The optimal regression function of Support Vector Machine (SVM) follows the principle of minimizing the structural risk. The regression problem is turned to a constraint optimization problem, namely:

$$
\begin{aligned}
& \min _{w, b, e} J(w, e)=\frac{1}{2}\|w\|^{2}+\gamma \sum_{i=1}^{n} e_{i}^{2} \\
& \text { S.t. } y_{i}=w^{T} \phi\left(x_{i}\right)+b+e_{i}
\end{aligned}
$$

where, $e_{i}$ is the error, $\gamma$ is the constant number, $x_{i}$ is the $i^{\text {th }}$ component of training samples inputting $X=\left(x_{1}, \ldots, x_{i}, \ldots\right.$, $\left.x_{n}\right), y_{i}$ is the $i^{\text {th }}$ component of $Y=\left(y_{1}, \ldots, y_{i}, \ldots, y_{n}\right)$. 
Establishing the Lagrange equation according to the duality theorem and introduce the Lagrange factor $a_{i}$, there is:

$$
L(w, e, b, a)=J(w, e)-\sum_{i=1}^{n} a_{i}\left\{w^{T} \phi\left(x_{i}\right)+b+e_{i}-y_{i}\right\}
$$

According to the Karush-Kuhn-Tucker theorem, LSSVR regression function is obtained :

$$
f(x)=\sum_{i=1}^{n} a_{i} K\left(x_{i}, x\right)+b
$$

Space mapping is realized through kernel functions. Common kernel functions include the linear kernel function, the polynomial kernel function, kernel of radial basis function, the Sigmoid Kernel function, etc. Results show that the radial basis function support vector machine possesses favourable generalization and learning ability, thus it is chosen to do the experiment:

$$
K\left(x_{i}, x\right)=\exp \left(-\frac{\left\|x_{i}-x\right\|^{2}}{2 \sigma^{2}}\right)
$$

In Eq. (7), the regular parameter $\gamma$ determines the penalty on samples that go beyond the accepted error and the complexity of the model. In Eq. (10), parameter $\sigma$ is the width of the kernel of radial basis function. The larger the value is, the less accuracy the fitting will be but the stronger the generalization will be. Therefore, to select the correct parameter $\gamma$ and $\sigma$ is significant to the accuracy of the model.

\section{Flow chart of AR-LSSVR model}

To put it simple, the AR-LSSVR prediction model combines the prediction algorithm advantage of the LSSVR and the AR model and makes complementary of the two to enhance prediction accuracy.

As time goes by and with the accumulation of stress damage, electronic devices inevitably present non-linear regression in their life span. Moreover, affected by tolerance, current drift and noises, failure samples possess linear stochastic characteristics. The LSSVR model has a preeminent non-linear tendency in terms of prediction performance and the AR Model performs well in stable linear random sequence. If the two are combined, the accuracy of failure prediction of electronic devices can be largely enhanced theoretically.

As a result, this thesis combines two models together. Firstly, it applies the least square support vector regression to non-stationary time series to obtain trend term $y(t)$. Then, it erases the trend term of the original sequence and obtains stochastic term $\varepsilon_{t}$ which is stable and normally distributed and of zero mean. Last but not the least, the trend term model and the stochastic term model are superposed to get the non-stationary time series LSSVR-AR model, as shown in Eq. (11). Fig. 2 shows its basis flow.

$$
Y(t)=y(t)+\varepsilon_{t}
$$

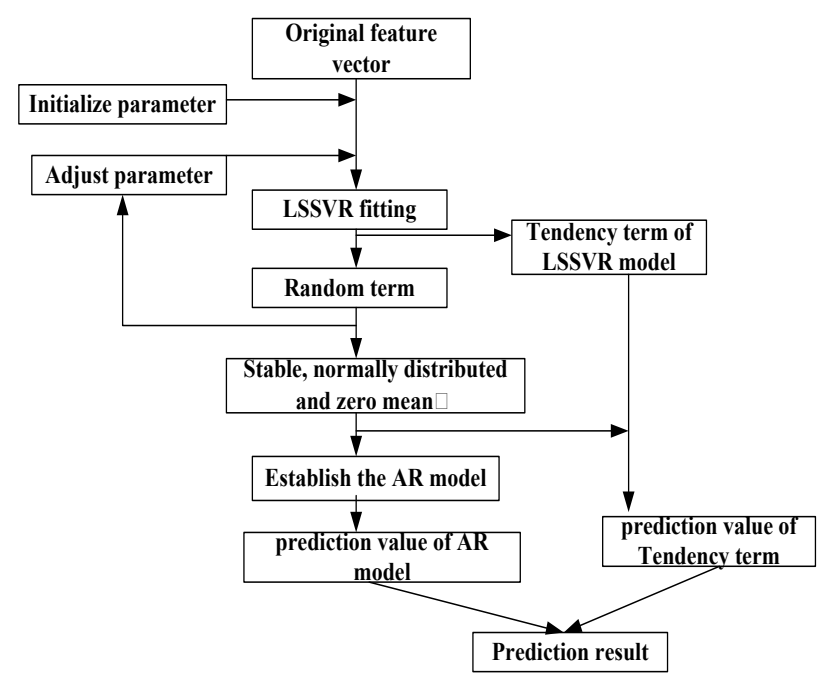

Figure 2 Flow chart of fault trend prediction based on AR-LSSVR

\section{Regression prediction of electrolytic capacitor performance based on the AR-LSSVR model}

In response to this, the thesis studies performance regression of electrolytic capacitor with typical power electronic circuits Buck circus as the research object. It verifies the failure prediction ability of the AR-LSSVR model on electronic devices.

\subsection{Reasons for failure}

In power electronic circuits, the electrolytic capacitor mainly serves as smoothing, accumulating energy and filters alternating voltage. Despite the abnormal failure due to some occasional causes, most failures of electrolytic capacitor are caused by the gradual evaporation and exhaustion of electrolyte as time goes by, which is a slow failure. Fig. 3 is its equivalent circuit diagram:

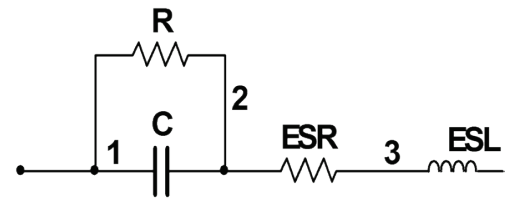

Figure 3 Equivalent circuit of electrolytic capacitor

$E S R$ is the equivalent series resistance of the capacitor, $C$ is the equivalent series capacitor, ESL is the equivalent series inductance, and $R$ is the equivalent leakage parallel resistance. In application, since the figure of $R$ and ESL is small, the series of $C$ and ESR can be regarded as the circuit model of the electrolytic capacitor. The working environment of the electrolytic capacitor has a great influence on measuring its circuit parameters, especially the working temperature and frequency.

As many studies show, in the equivalent electrolytic capacitor circuit model, a rational way to evaluate the performance of the electrolytic capacitor is to measure the equivalent series resistance. As time goes by, the electrolyte evaporates, and the equivalent series resistance also changes. Reference [14] concluded the trend of the 
equivalent series resistance's change as time goes by in Eq. (12):

$$
\frac{1}{\operatorname{ESR}(t)}=\frac{1}{\operatorname{ESR}(0)} \cdot\left(1-k \cdot t \cdot e^{-\frac{4700}{T+273}}\right)
$$

In Eq. (12), $\operatorname{ESR}(t)$ is the $E S R$ figure at time $t$ in $T$ temperature, $T$ is the internal temperature of the capacitor (unit is Celsius degree), $\operatorname{ESR}(0)$ is the $\operatorname{ESR}$ figure at the initial moment in $T$ temperature, and $k$ is the constant determined by design and structural parameter of the capacitor. Influenced by some occasional factors, the trend of the ESR of the equivalent series resistance in its life cycle is not a smooth curve, and thus the figure should be:

$$
\operatorname{ESR}^{*} i_{c}(t)=\operatorname{ESR}(t)+\varepsilon(t)
$$

$\varepsilon(t)$ is the random sequence number at time $t$. Thus, according to the above analysis, by putting $T, \operatorname{ESR}(0), K$ and $\varepsilon(t)$ into Eq. (13), the researcher can get the trend in this working environment.

\subsection{Characteristic parameter extraction}

$E S R$ of the equivalent series resistance is the best parameter to evaluate the performance of electrolytic capacitor. However, when the circuit is operating, ESR cannot be measured directly. Therefore, if the ESR is chosen as the failure feature parameter to evaluate the performance of the electrolytic capacitor, right detection signals need to be selected and the relation between the detection signals and ESR needs to be found out, and then $E S R$ can be calculated indirectly.

Extracting the failure feature parameter of the electrolytic is a key part for failure diagnosis and prediction of electrolytic capacitor. This sector uses time domain analysis as the example to study the failure feature detection method for electrolytic capacitor. Based on the equivalent electrolytic capacitor circuit model, its circuit equation is shown in Eq. (14):

$$
\operatorname{ESR}^{*} i_{c}(t)+u_{c}(t)=u_{o}(t)
$$

In the equation, $i_{c}(t)$ is the current through the capacitor at time $t, u_{c}(t)$ is the voltage of the equivalent series capacitor, and $u_{o}(t)$ is the output voltage of the capacitor. According to the equation for capacity charge, $u_{c}(t)$ can be calculated in Eq. (15):

$$
u_{c}(t)=\frac{1}{C} \int_{0}^{t} i_{c}(t) \mathrm{d} t+\mu
$$

In Eq. (16), $u_{c}(0)$ is the voltage of the equivalent series capacitor at the initial moment.

$$
u_{c}(0)=u_{o}(0)-\operatorname{ESR}^{*} i_{c}(0)
$$

The relation between the ESR and the output voltage and capacitive current at time $\mathrm{t}$ is shown in Eq. (17):

$$
E S R^{*} i_{c}(t)+\frac{1}{C} \int_{0}^{t} i_{c}(t) \mathrm{d} t+u_{o}(o)-E S R^{*} i_{c}(0)=u_{o}(t)
$$

If the output voltage $u_{o}$ and the capacitive current $i_{c}$ at the two sides of the capacitor are selected as monitor signals, both the figure of detection signals at the initial moment and at any other moment, the integral figure of the capacitive current at the corresponding moment, can be calculated. Through the linear equation group, the parameter of the equivalent capacitor circuit can be got. For example, if signals at $t_{1}, t_{2}$ are extracted, the equation group is shown in Eq. (18).

$$
\begin{aligned}
& E S R^{*} i_{c}\left(t_{1}\right)+\frac{1}{C} \int_{0}^{t_{1}} i_{c}(t) \mathrm{d} t+u_{o}(o)-\operatorname{ESR}^{*} i_{c}(0)=u_{o}\left(t_{1}\right) \\
& \operatorname{ESR}^{*} i_{c}\left(t_{2}\right)+\frac{1}{C} \int_{0}^{t_{2}} i_{c}(t) \mathrm{d} t+u_{o}(o)-E S R^{*} i_{c}(0)=u_{o}\left(t_{2}\right)
\end{aligned}
$$

\subsection{Setting Buck circuit and simulation parameter}

In this section, Multisim is used to simulate the circuit to show the performance of the circuit influenced by electrolytic capacitor in different conditions. Matlab time domain analysis is used to extract the characteristic parameter of the electrolytic capacitor.

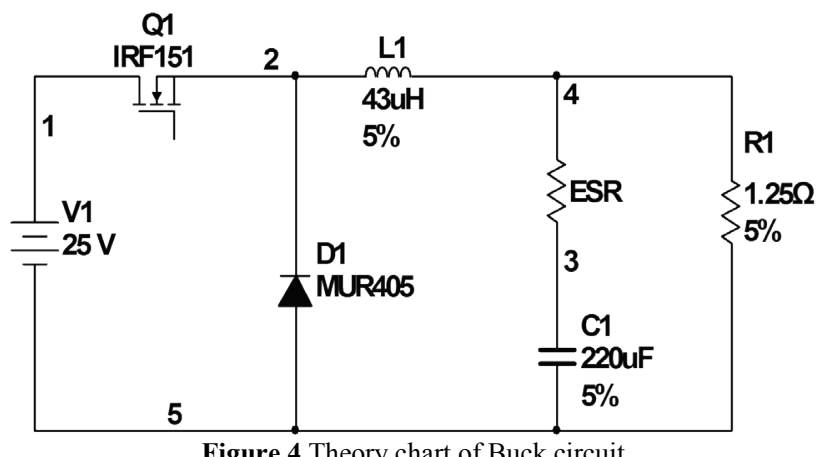

Fig. 4 shows the basic principle of buck circuit. The switching tube is IRF151, frequency $f=50 \mathrm{kHz}$, duty ratio is 0,22 , inductance is $43 \mathrm{Mh}$ with $5 \%$ tolerance, electrolytic capacitor $C=220 \mu \mathrm{F}$ with $5 \%$ tolerance, load $\mathrm{R} 1$ is $1,25 \Omega$ with $5 \%$ tolerance, D1 is fly back diode, and the voltage drop is $0,5 \mathrm{~V}$. This circuit can realize the transformation of DC-DC with the input V1 of $25 \mathrm{~V}$ to the steady state output of $5 \mathrm{~V}$.

According to the requirement of the circuit for the electrolytic capacitor, electrolytic capacitor is set as $C=$ $220 \mu \mathrm{F}$, the rated making-capacity voltage is $35 \mathrm{~V}$ and temperature $\mathrm{T}$ is $40{ }^{\circ} \mathrm{C}$. In certain temperature and frequency, $\operatorname{ESR}(0)$ is $0,45 \Omega, k$ is $4,35 \times 10^{4}$. Based on Eq. (12), if the life cycle is set as 50, the ESR of the electrolytic capacitor in the simulation will change as Fig. 5 shows. The horizontal axis shows the life time, and the vertical axis shows the ESR practicality trend of the electrolytic capacitor. 


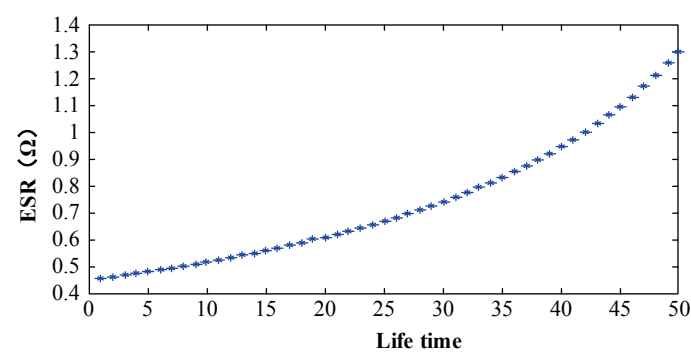

Figure 5 ESR practicality trend of electrolytic capacitor

If buck circuit goes through the transient analysis, with the sampling time of $1 \mathrm{~ms}$, the trend of $u_{o}$ and $i_{c}$ can be illustrated in Fig. 6 and Fig. 7 respectively.

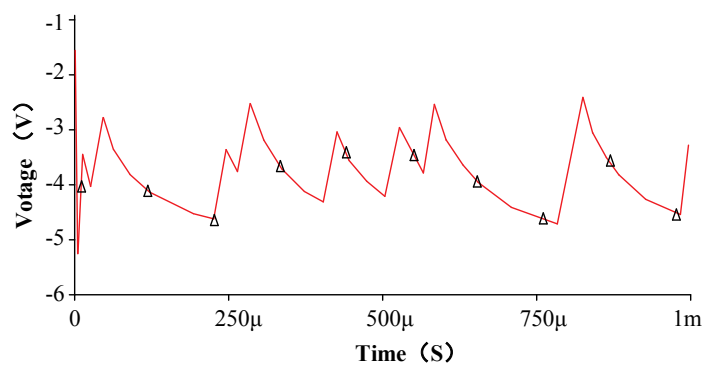

Figure 6 Transition voltage of fan-out

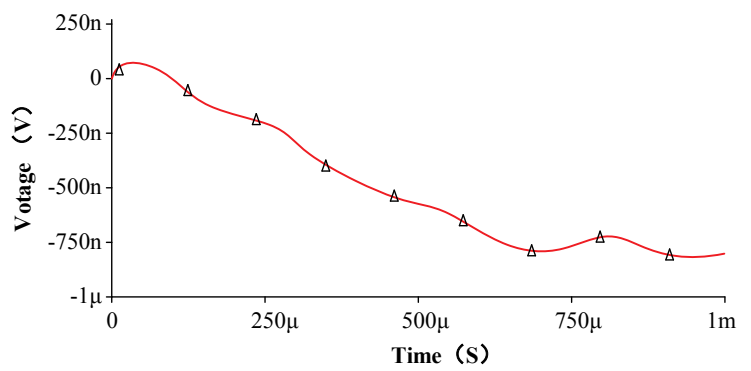

Figure 7 Transition current of ESR

The horizontal axis shows the lifetime, and the vertical axis shows the ESR practicality trend of electrolytic capacitor in Fig. 6. The horizontal axis shows the running time, and the vertical axis shows the transition current of ESR in Fig. 7.

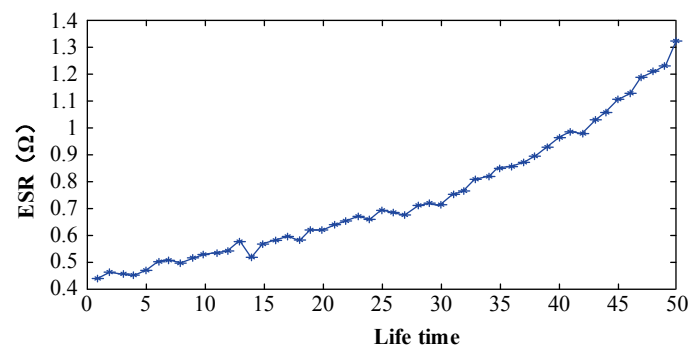

Figure 8 ESR practicality trend sampled from Buck circuit

At every point, if the simulation figure of $E S R$ is put into the circuit, the trend of ESR figure of the series resistance is shown in Fig. 8 according to Eq. (18). The horizontal axis shows the lifetime, and the vertical axis shows the practicality trend of ESR sampled from Buck circuit. The ESR figure is distributed randomly with certain trend for the influence of the circuit tolerance is regarded as that caused by some occasional factors in application. Therefore, the sample needed for prediction is obtained.

\subsection{The prediction for the performance regression of AR- LSSVR}

Analyse the above samples. The former 30 are training samples, and the latter 20 are testing samples. These samples are modelled and simulated according to the AR-LSSVR prediction model.

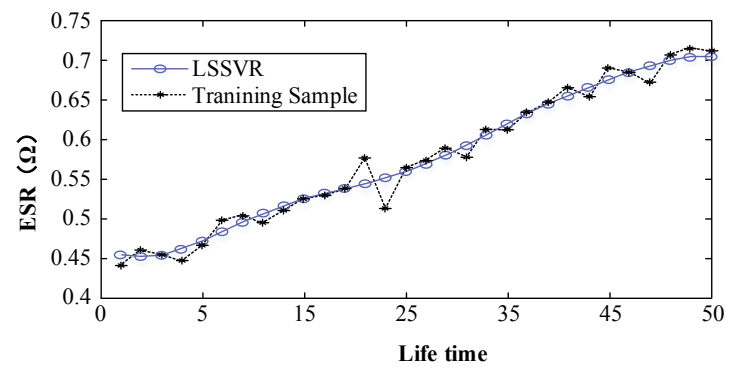

Figure 9 Sketch maps of data that was drawn with training sample based on LSSVR

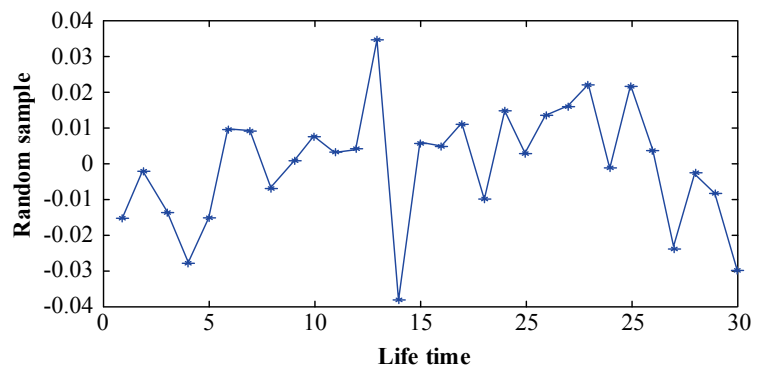

Figure 10 Random samples of training data

The training samples fit the LSSVR model. Trend term got in LSSVR model is shown in Fig. 9. The horizontal axis shows the lifetime, and the vertical axis shows the prediction results based on LSSVR method. The stochastic term is obtained after the trend term of training samples is omitted in Fig. 10. The horizontal axis shows the lifetime, and the vertical axis shows the random samples of training data. They fit stochastic term in AR model. Parameter estimation and autocorrelation is done for the stochastic term, and the results are shown in Fig. 11 and Fig. 12. The horizontal axis shows the estimate value, and the vertical axis shows the approximate estimate distribution in Fig. 11. The horizontal axis shows the lifetime, and the vertical axis shows the auto collection in Fig. 12. It can be perceived that stochastic tern is almost of zero mean normal distribution, and is correlated, and thus it can be fitted in AR model. For samples with complex change, one-step prediction is better than multistep one. Thus, one-step prediction AR model is selected to fit the sample of stochastic term.

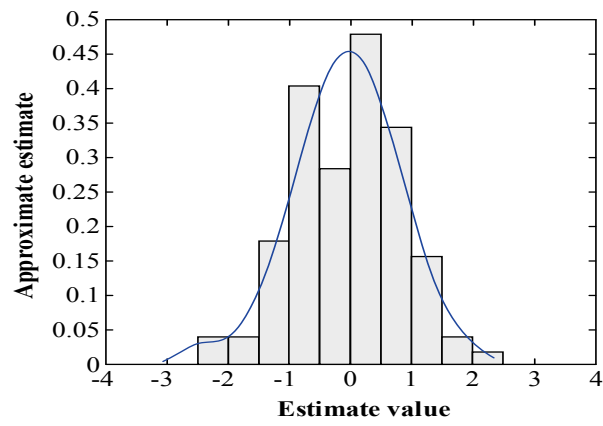

Figure 11The chart of approximate estimate 


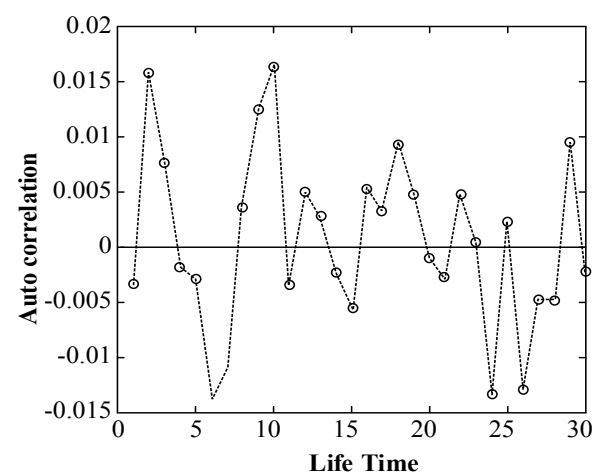

Figure 12 Sketch map of auto correlation

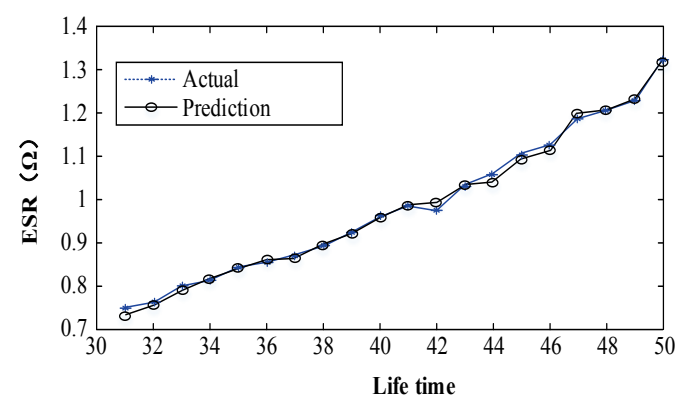

Figure 13 Prediction results based on AR-LSSVR

Combine the adapted trend term LSSVR model and AR model, and obtain the non-stationary time series ARLSSVR prediction model. Predict testing samples by ARLSSVR model and results are shown in Fig. 13. The horizontal axis shows the lifetime, and the vertical axis shows the prediction results based on AR-LSSVR method.

\subsection{Result analysis}

The mean absolute percentage error is chosen as the prediction evaluation index. It is calculated as:

$G=\frac{1}{n} \sum_{i=1}^{n}\left|\frac{Y_{i}-\hat{Y}_{i}}{Y_{i}}\right| \times 100 \%$

where $Y_{i}$ is the actual value, $\hat{Y}_{i}$ is the prediction value, $\mathrm{n}$ is the number of testing samples. According to Eq. (19), the mean absolute error of AR-LSSVR model to electrolytic capacitor for condition trend prediction is $5,387 \%$. The results of LSSVR prediction model are obtained, whose mean absolute percentage error is 11,229 $\%$. The AR model is not discussed in this thesis, as it cannot make prediction on changeable samples independently.

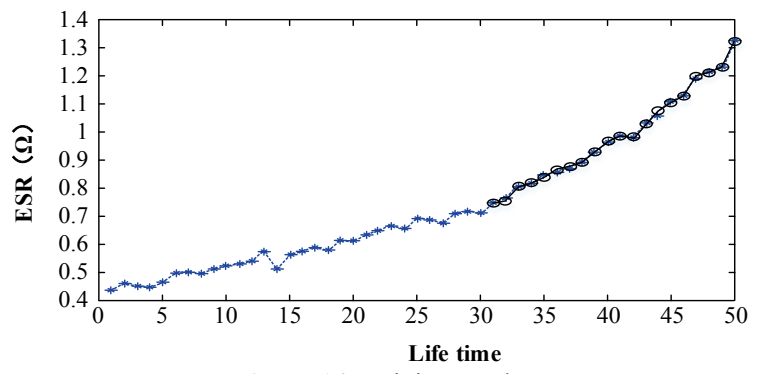

Figure 14 Training results
Results indicate that the AR-LSSVR model performs better than simple LSSVR model with regard to condition trend prediction of electrolytic capacitor. Fig. 14 shows the prediction results of full-life cycle samples. The horizontal axis shows the lifetime, and the vertical axis shows the training results based on AR-LSSVR method.

\section{Conclusion}

The paper puts forward a method of fault prognostic based on AR-LSSVR for electrolytic capacitor. Because the electrolytic capacitor is low in cost and large in volume, it is widely used in power electronic circuits. Firstly it introduces the basic model and the fault prognostic algorithm of the AR, LSSVR and AR-LSSVR. The AR-LSSVR prediction model combines the prediction algorithm advantage of the LSSVR and the AR model and makes complementary of the two to enhance prediction accuracy. It introduces the flow chart of fault trend prediction based on AR-LSSVR. Finally, the ARLSSVR model is applied to the Buck circuit. The results indicate that the AR-LSSVR model performs better than simple LSSVR model with regard to condition trend prediction of electrolytic capacitor.

\section{Acknowledgements}

This work is supported by the National Defence Preresearch Foundation 9140A27020113JB11393 and 9140A27020314JB11438

\section{References}

[1] Yin, M.; Ye, X. H.; Chen, S. C. Sensor Selection and Location Scheme for Prognostic and Health Management. // Sensorsand Transducers. 158, 11(2013), pp. 230-235.

[2] Alam, M. A.; Azarian, M. H.; Osterman, M.; Pecht, M. Prognostics of Failures in Embedded Planar Capacitors using Model-Based and Data-Driven Approaches. // Journal of Intelligent Material Systems \& Structures. 22, 12(2011), pp. 1293-1304. DOI: 10.1177/1045389X11416024

[3] Fan, G.; Ma, D. W.; Zhang, J. J. Gradual fault prediction method for electronic system based on adaptive RVM. // Journal of Beijing University of Aeronautics and Astronautics. 39, 10(2013), pp. 1319-1324.

[4] Qi, T.; Zhang, Y. B. Analog Circuit Fault Prediction Based onLS-SVM Optimized by PSO. // Computer Measurement \& Control. 24, 3(2016), pp. 4-7.

[5] Jiang, Y. Y.; Wang, Y. R.; Luo, H. et al. An Innovative Metric for Power Electronic Circuit Failure Evaluation and a Novel Prediction Method Based on LSSVM. // Transactions of China electro-technical Society. 27, 12(2012), pp. 43-52.

[6] Zhang, A. H.; Wang, Y. C.; Song X. D. et al. Novel online evaluation strategy for analog circuit performance based modified robust LSSVR. // Chinese Journal of Scientific Instrument. 34, 10(2013), pp. 2328-2335.

[7] Lu, K. S. Failure Prediction for an On-Line Maintenance System in a Poisson Shock Environment. // IEEE Transactions on Systems Man \& Cybernetics. 9, 6(1978), pp. 356-362.

[8] Gadzheva, E. D.; Raykovska, L. H. Nullator-norator approach to analogue circuit diagnosis using generalpurpose analysis programmes. // International Journal of Circuit Theory \& Applications. 23, 6(1995), pp. 571-585. DOI: $10.1002 /$ cta.4490230603 
[9] Rabiner, L. R. A tutorial on hidden Markov models and selected applications in speech recognition. // Proceedings of the IEEE. 77, 2(1989), pp. 267-296. DOI: 10.1109/5.18626

[10] Ginart, A. E.; Brown, D. W.; Kalgren, P. W. et al. Online ringing characterization as a diagnostic technique for IGBTs in power drives. // IEEE Transactions on Instrumentation \& Measurement. 58, 7(2009), pp. 22902299. DOI: $10.1109 /$ TIM.2009.2013920

[11] An, Q. T.; Sun, L. Z.; Zhao, K. et al. Switching function model-based fast-diagnostic method of open-switch faults in inverters without sensors. // IEEE Transactions on Power Electronics. 26, 1(2011), pp. 119-126. DOI: 10.1109/TPEL.2010.2052472

[12] Alwitt, R. S.; Hills, R. G. The chemistry of failure of aluminum electrolytic capacitors. // IEEE Transactions on Parts Materials \& Packaging. 1, 2(1964), pp. 28-34. DOI: 10.1109/TPMP.1965.1135396

[13] Lahyani, A.; Venet, P.; Grellet G. et al. Failure prediction of electrolytic capacitors during operation of a switch mode power supply. // IEEE Transactions on Power Electronics. 13, 6(1998), pp. 1199-1207. DOI: 10.1109/63.728347

[14] Sarathi Vasan, A. S.; Long, B.; Pecht, M. Diagnostics and prognostics method for analog electronic circuits. //IEEE Transactions on Industrial Electronics. 60, 11(2013), pp. 5277-5291. DOI: 10.1109/TIE.2012.2224074

[15] Salat, R.; Osowski, S. Analog filter diagnosis using Support Vector Machine. // ECCTD. 2, (1987), pp. 421-424.

[16] Milne, R.; Bain, E.; Drummond M. Predicting faults with real-time diagnosis. // Decision and Control, Proceedings of the 30th IEEE Conference on IEEE. 3, (1991), pp. 25982603.

[17] Zhu, Y. L.; Zhao, W. Q.; Zhai, X. M. et al. A fault prediction approach for power transformer based on support vector machine. // 2007 International Conference on Wavelet Analysis and Pattern Recognition, ICWAPR. 4, (2007), pp. 1457-1461.

\section{Authors' addresses}

\section{Ming Yin}

Corresponding author

College of Electronic Engineering,

Naval University of Engineering,

Jiefang Dadao No. 717, Qiaokou district, 430033 Wuhan,

Hubei Province, China

E-mail: 569121080@qq.com

\section{Yanyi $X u$}

Department of Information Secure,

Navy University of Engineering,

Jiefang Dadao No. 717, Qiaokou district, 430033 Wuhan, Hubei Province, China

E-mail: 3692541362@qq.com

\section{Xiaohui Ye}

Departmentof Scientific research,

Naval University of Engineering,

Jiefang Dadao No. 717, Qiaokou district, 430033 Wuhan, Hubei Province, China

E-mail: xiaohui_y@163.com

\section{Shaochang Chen}

College of Electronic Engineering,

Naval University of Engineering,

Jiefang Dadao No. 717, Qiaokou district, 430033 Wuhan,

Hubei Province, China

E-mail: SCChen@163.com

\section{Hongxia Wang}

College of Electronic Engineering,

Naval University of Engineering,

Jiefang Dadao No. 717, Qiaokou district, 430033 Wuhan, Hubei Province, China

E-mail: 3365215462@qq.com

\section{Feng Xie}

College of Electronic Engineering,

Naval University of Engineering,

Jiefang Dadao No. 717, Qiaokou district, 430033 Wuhan,

Hubei Province, China

E-mail: 85628859@qq.com 